\title{
The Application Research of Regional Culture Elements in the Interior Design
}

\author{
Rong Xiong \\ Polytechnic Institute of Jiangxi Science and Technology Normal University, China
}

Keywords: Regional culture, the cultural element, interior design, application

\begin{abstract}
In today's world of cultural development, a return to traditional cultural phenomenon has become irreversible. About the regional characteristics of architecture, this paper aims to explore, on the basis of the traditional, regional culture elements in the application of interior design, especially in the use of the design space.
\end{abstract}

\section{Introduction}

In today's world of cultural development, the traditional regression has become irreversible cultural phenomenon; people gradually became calm and mature, start thinking about you, and to explore the nation and the development of contemporary design and regional culture of organic integration. In recent years, the annual national interior design competition entries, it is not difficult to found that many of the more successful works are the integration in the design of regionalist and nationality, its space culture as the soul of a designer to design different geographical regions [1].

With the continuous improvement of quality of life of survival environment began to reconsider and thus put forward higher requirements. Especially the improvement of living level and cultural quality of people live in a environment with classic beauty rhyme to enjoy my life is so sweet and satisfied [1]. Interior design is including the display space environment, indoor decoration, decoration, building interior space of the integrated design system, covers the entire content of the functional and aesthetic represents the mainstream of the modern world.

\section{The problems existing in the modern interior design}

Interior design is based on the structure of the use of nature, environment and the corresponding standards, using the material technical means and architectural aesthetics principle, create function reasonable, comfortable beautiful, and satisfy people material and spiritual life need of the indoor environment [1]. This one space environment has both use value, meet the functional requirements, but also reflects the historical context, architectural style, mental factors such as environment atmosphere. Problem of modern indoor environment design in our country is mainly manifested in the following points:

\subsection{Performance in design is heavy, light culture shape.}

Buildings is a kind of cultural phenomenon, is the important carrier of human civilization. To gather and carrier of the city and architecture, is a national culture status, the most centralized embodiment of civilization, is the concentrated in the country. The wave of globalization swept by, we see the "autonomy" of China's modern culture and traditional Chinese culture of the lost, specific to the architecture and environment art, prominent status is churning out "the Bauhaus" architecture throughout, tastelessness of the proliferation of "false" of Europe land amorous feelings. Imitation, the phenomenon of plagiarism, the pursuit of luxury in the design work can be seen everywhere, bright strong regional culture characteristics in most cities in today's China is decreasing, it is related to lots of traditional culture and social blundering, investigate its reason, both the lost of culture, there is also a lack of institutional [2]. This is the city policy makers and designers must face the serious and urgent problem. 


\subsection{Lack of humanistic care in the design process.}

It is the fundamental purpose of interior design is not driven by material, our behaviors and life needs is the basic reference to interior design, which is by the people and external environment of the non-deterministic relationship decisions (namely nature didn't provide a ready-made living conditions, but through their own changes to the environment for their services, people and animals is that man in the world to foreign inevitable transcendence), with the development of social economy, people more and more high request to the quality of their life, it is the requirement to promote chamber [2].

\subsection{In the design development.}

People and the social demand is the motive force of social development, so people endless pursuit to become the lifeblood of the interior design update. Indoor environment design must seize people's strong desire to improve the quality of living environment, in the person of this kind of mentality and product development, such as indoor environment more perfect construction, such as modern residential, villa, the construction of the new type of commercial space, etc.) Play an important role in the mediation.

\section{The organic fusion of regional culture element and space design}

All designers have to face the reality conditions, can't get away from the real economic condition, and depend on the technical possibilities of the material and transformation, so we should confront with normal building materials to create the so-called "modern space". This is the application of regional culture and folk elements in space we face a problem; Shape the space not only expensive material or several national symbols to express the culture idea and design connotation, and should be from the space layout, the propylene, the wall with the transition to conception of space [2]. Chinese traditional local-style dwelling houses and garden design in architectural culture in modern architecture and indoor environment design, let a space "actual" combined with "artistic conception", walks different scene, winding path leading to a secluded spot. So "person" as the carrier of the space is rich deeper culture and stronger vitality. "Space artistic conception" is the soul of design. Inclination of Engels said: "don't say specifically, and will naturally from the plot".

In the traditional Chinese interior design is often the pursuit of harmony with nature and can adjust measures to local conditions; Pay attention to the overall unity, order and symmetry; Emphasis on implicit begets plain, false or true, complement each other, mutual penetration is the fundamental design. Attaches great importance to the modeling of freehand brushwork in the interior design exaggerated omitted for the purpose of god [3]. The use of all key elements of interior design is to create artistic conception, and in be being designed indoors, use a lot of symbolism meaning. From the decorative form of organization to the indoor and outdoor space: from decoration materials to decorate structure full of the spirit connotation of contracted and rich connotation design represent the cultural heritage and provide a person infinite daydream.

\subsection{The traditional pattern of extended meanings.}

The subject of Chinese traditional decorative pattern roughly divided into two categories: one is decorating pattern, the second is moral pattern, but the line is not so obvious, the vast majority of decorating pattern also has all kinds of auspicious implies at the same time, its design itself has a certain image [3].

\subsection{Symbolic significance.}

In the traditional Chinese interior decoration, traditional decorative pattern plays a very important role, whether building doors and Windows, patio, the adornment such as beams, or indoor screen, partition, furniture, and the bottle glass display, calligraphy and painting, such as hanging, and bed curtain, curtain, cushion, wallpaper, spelling a flower on the ground, etc. , cannot leave the traditional decoration pattern, to the degree to which any act the role offing, not sorry, is an important part of Chinese traditional interior decoration design [4]. Traditional decorative pattern in modern interior 
can be dealt with through to surround close interface of decoration, choose a traditional pattern decoration indoor display is tasted. Surround close interface namely metope, ground, ceiling, including the disjunctive space entities and entity, indoor display is tasted refers mainly to furniture, equipment, indoor decorative fabric, display art, lighting, etc. They use in the space of the modern design, through to the modeling and pattern identification and interpretation, make a design can not only satisfy the pursuit of functional and rational, and can reflect the traditional culture traits, psychological resonance, and work experience of humanistic care, satisfy the people to a higher level of spiritual and psychological needs.

\subsection{The reasonable application of decorative materials.}

The implementation of the indoor design, Chinese style must be done through materials, modern society, can be used in indoor environment is the material a lot, but to achieve reasonable use is more difficult, we should learn to take the initiative to control the material, maximum material into full play [4].

\subsection{Wood Cultural elements.}

Wood, as a kind of lightsome, is warm and strong material, have a good touch, smell and plasticity. Human as early as in ancient times had a lot of the natural attribute of lumber into the civilization of the society at that time, such as the carved totem worship. It is strong wood [5]. Affinity and sense of belonging and become the closest living material, human life was as the main material of floor, wall and furniture, shown as Fig. 1.

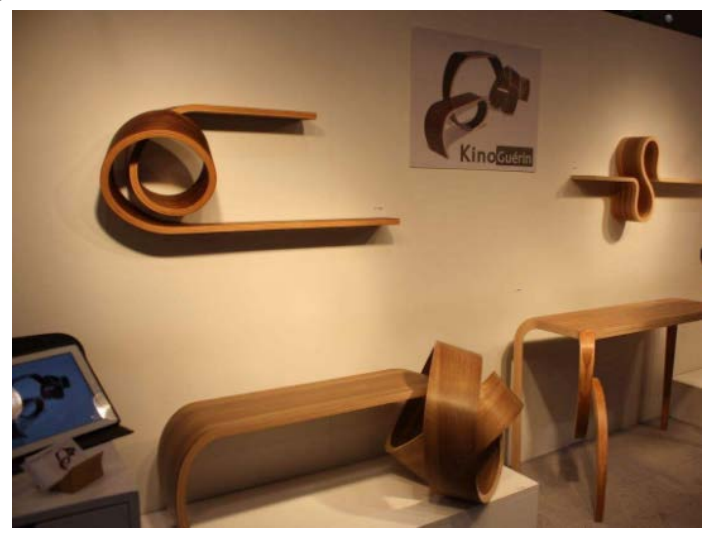

Fig. 1 Wood Cultural elements application in interior design

\subsection{Bamboo Cultural elements.}

Bamboo qualitative decoration materials mainly include bamboo flooring, wall panel, bamboo line, bamboo furniture, bamboo board and other new type of green environmental protection material, such as Fig. 2.

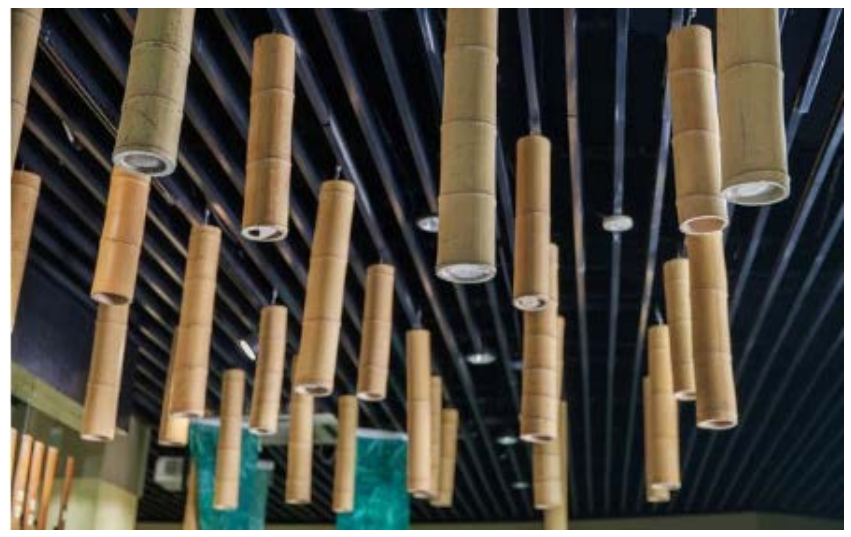

Fig. 2 Bamboo Cultural elements application in interior design

In todays advocate natural and the "green decoration", bamboo floor with its excellent internal quality and aesthetically pleasing appearance, by gradually. Bamboo floor texture straight, elegant 
tone, smooth texture, and can add indoor culture atmosphere, very suitable for as a ground decorates material.

\subsection{Stone Cultural elements.}

To make since ancient times, from the structure of the building, to the shop is on the surface of the building, the building environment of decoration, stone has been playing an important role [5]. The art of carving stone material selection, group of Taiwan, can give the space environment of different personality and charm. Stone is the most attractive colour and lustre is the feature of grain can keep the original rock of natural style and features, and allocate change color; stone texture can be connotation and art show, such as Fig 3. Match people advocate natural, return to natural culture idea, people referred to this kind of stone material as "culture Stone ". With this kind of decorative stone walls, paved the ground, wall made of landscape, etc. , can give a kind of Chinese culture and the natural breath.

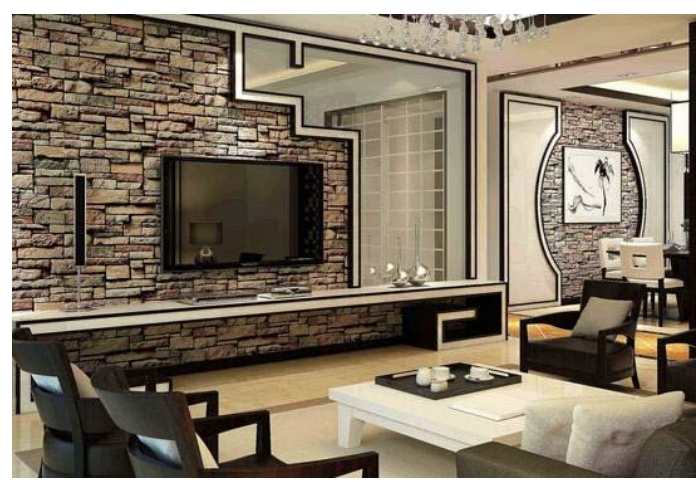

Fig. 3 Stone Cultural elements application in interior design

\subsection{Chinese style style of the bedroom colour emotion performance.}

Color by visual effects on psychological; often affect the person's emotion, about people's spirit and behavior. In be being designed indoors, the choice of the color for indoor overall environment plays a very important role to the foil atmosphere. Throughout our country traditional buildings live ring, north of the palace, Yamuna building modeling elegant, bright colorful, are comparative and intense [6]. In Yixing, evergreen south local-style dwelling houses building, in order to make the building color to reconcile the natural environment in the south, it USES the colour is quietly elegant,

Use white walls and gray tiles and chestnut beams, such as black, dark green color, form the style of quietly elegant beautiful. The modern interior design with the color of Chinese style of the emotional hold to under the premise that meet people's emotional needs inheritance and innovation of traditional color. Such as wall cloth color matching, according to the overall tone at indoor, and deal with other items (such as a wall lamp, decoration, etc. ) have foil effect [6]. And as in most shallow light soft tone of interior space, always appear beyond the mark and harmonious and bland, we adjust the whole, if proper position on the wall hangs the adornment picture three two more gorgeous colour saturation, the atmosphere of whole space will be in this kind of element and bright contrast. In fact, there are many ways to mix colors, especially with a similar colour or adjacent colour harmony principles are more widely used. All in all, the ultimate purpose of color harmony is to make interior atmosphere reached some kind of emotional appeal, more conducive to meet the psychological needs of people.

\subsection{Natural landscape of Chinese style mixed set off.}

With the increasing deterioration of the ecological environment, people longing for nature with a warm, natural elements for some related subject construction has a profound significance. Human nature, and in harmony with nature, is the human nature, whether physical or psychological, people are willing to close to nature, natural environment, and modern society just keep people away from the nature, life for a long time in artificial environment. Therefore, how to give vitality to the indoor environment has become today's designer's face in interior design. 


\section{Summary}

Our from countries around the world can also be seen in the contemporary some outstanding works, their cultural heritage and use is not the same, because if it can only be archaize to restore ancient ways, can be to move, we advocate should be combined with the needs of The Times; Way to embody national verve of interior design creation now in our country the Chinese element is widely used in interior design work is that it's position in the design is very widely used. The essence of traditional culture, on the basis of the traditional and new, can make the design work coruscate gives new vitality. To achieve such depth, of course, our designers need to continue to make great efforts to study the local traditional architecture and interior decoration culture, can comprehend the, went up from the spirit of traditional culture rather than merely stay on the surface of imitation; In first-class "the distribution", to make Chinese contemporary architecture and interior design in the world.

\section{References}

[1] R.H. Xu. Contemporary interior design ideas about, Journal of interior design, 2003, vol. 2, pp. 22-24.

[2] Y.T. Dan and Sh.L. Wang, The application of traditional decoration pattern in China building decoration, Journal of furniture and interior decoration, 2006, vol. 3, pp. 50-52.

[3] R. Q. Zhou, Building design with Regional culture elements, Beijing: China planning press, 1999, pp. 23-26.

[4] J.B. Zhou, Implicative beauty overall design, Journal of interior design and decoration, 2001, vol. 5, pp. 40-44.

[5] Y. T. Huang, The application research of the era of large data, Computer programming skills and maintenance, 2014, vol. 8, pp. 25-28.

[6] F. J. Dong, Regional culture elements garden aesthetics research, Journal of decoration, 2005, vol. 6, pp. 75-78. 